\title{
ANALYSIS OF VIBROACOUSTIC SIGNALS RECORDED IN THE PASSENGER LIFT CABIN
}

\author{
Kamil Szydło', Paweł Maciąg², Rafał Longwic', Małgorzata Lotko² \\ 1 Department of Automotive Vehicles, Lublin University of Technology, Nadbystrzycka 36, $20-618$ Lublin, \\ Poland, e-mail: kamil-szydlo@wp.pl; r.longwic@pollub.pl \\ 2 University of Technology and Humanities in Radom, Malczewskiego 29, 26-600 Radom, Poland
}

Received: 2016.04 .25

Accepted: 2016.05.15

Published: 2016.06.01

\begin{abstract}
The analysis of private tests is presented in the article. The applicable tests refer to accelerations, the level of the sound pressure as well as to the sound power emitted by the passenger lift cabin at different technical conditions of the lift. For a group of lifting devices the accelerations were tested at three axes with the use of an accelerometer. The accelerometer was placed in the central part of the cabin with simultaneous measurement of the acoustic parameters with the sound analyzer equipped with sound volume double microphone probe. An attempt was made to determine the impact of the frame - cabin system construction as well as the lift's technical condition on the recorded parameters. It can allow to establish the limit values of the lift structure parameters under which a rapid drop of comfort takes place, while travelling in the lift as well as to indicate those construction elements the modification of which would affect the improvement of the operation noiselessness.
\end{abstract}

Keywords: vibroisolations, sound measuring, noise emission.

\section{INTRODUCTION}

Lifting devices belong to vertical transportation machines which are commonly used in nearly each, new, multifamily housing. The current passenger lifts significantly differ from the lifts which were installed many years ago. Aiming at optimization of the structure in terms of the weight, manufacturing costs as well as energy consumption causes that more and more construction elements are represented by the products made of thin-walled materials. This is the way to achieve a compromise between price and quality. However, such activities generate a risk to decrease operation parameters which determine passengers' comfort. Comfort of the passengers who travel in the lift cabin should be understood as psychophysical state under which a travelling person feels good and safe. The applicable feeling can be influenced by the factors which do not depend on the construction directly. The authors can speak about such factors as ambient temperature, the cabin total volume and the light intensity (specified in PN81.21-1 standard) as well as the factors directly dependent on the construction such as vibrations or the sound volume level emitted by the slides, power drive and cabin walls. Figure 1 presents a roll slide of the lift with marked volumes of clearances. The clearances during the journey influence, to a large extent, the vibrations volume in the system consisting of the frame and the cabin.

Clearances appearing in the slides as well as the cabin walls construction (thin-walled elements resonance) directly influence the level of vibrations and the sound emission which are the parameters determining the feeling of comfort. These phenomena are also one of the forms of energy dissipation and they contribute to the overall device efficiency drop.

The aspects regarding the analysis of vibroacoustic phenomena in lifting devices were partially touched in the available literature. 


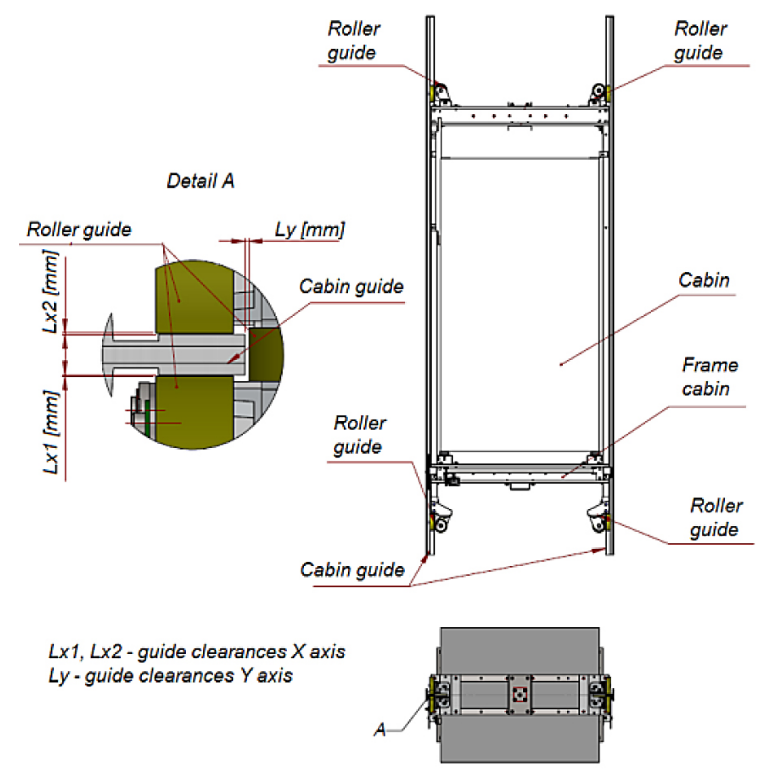

Fig. 1. Clearances present in the cabin slide of the passenger lift.

Mainly, it referred to:

- the volume of vibrations and noise coming from different lifting components such as the slides rollers [1-3];

- vibroinsulation methods for the lift doors power drive and the selection of vibroinsulation materials [4-9];

- measuring methods and reduction of acoustic emission in the passenger lifts cabins [10-13].

The analysis of available literature gives the evidence on the lack of publications regarding the methods saying how to use vibroacoustic phenomena to evaluate technical condition of the lifting devices. Herein, the technical condition is recognized as a set of parameters of the lift structure influencing the passengers' comfort.

Thus, the performed tests aimed at getting familiar with vibroacoustic phenomena appearing in the lifting devices. Moreover, the tests aimed at analyzing the above mentioned phenomena in the light of possibility to increase the construction noiselessness as well as to use them in the diagnosis process focusing on the passengers' comfort level monitoring.

\section{EMPIRICAL TESTING}

\section{The subject of testing}

Two passenger lifts were selected for the test. They have similar technical and operating parameters. The lifts parameters are presented in Table 1.
Table 1. Selected parameters compilation of tested lifts

\begin{tabular}{|l|c|c|}
\hline The lift serial number & The lift 1 & The lift 2 \\
\hline The year of installation & 2009 & 2012 \\
\hline Loading capacity Q [kg] & \multicolumn{2}{|c|}{450} \\
\hline Speed V [m/s] & 1,6 & 1,4 \\
\hline Lifting height H [m] & 21 & 28,3 \\
\hline The number of stops $\mathrm{n}$ & 7 & 9 \\
\hline The cabin depth A [m] & 1,150 & 1,180 \\
\hline The cabin width B [m] & 0,930 & 1,050 \\
\hline Type of a hoist & $\begin{array}{c}\text { single-speed, regulated, } \\
\text { with an encoder }\end{array}$ \\
\hline The engine room location & \multicolumn{2}{|c|}{ upper } \\
\hline Type of the slides & \multicolumn{2}{|c|}{ roll } \\
\hline The cabin walls construction & $\begin{array}{r}\text { panel type made of stain- } \\
\text { less steel }\end{array}$ \\
\hline
\end{tabular}

These are the lifts with increased speed typical for tall modern buildings. The scheme of tested devices is presented in the Figure 2. The operating time from the moment of installation was respectively 3 and 6 years. The times were selected in a such way that it could be possible to establish the differences within the level and the sound emission sources resulting from the lift elements wear and tear.

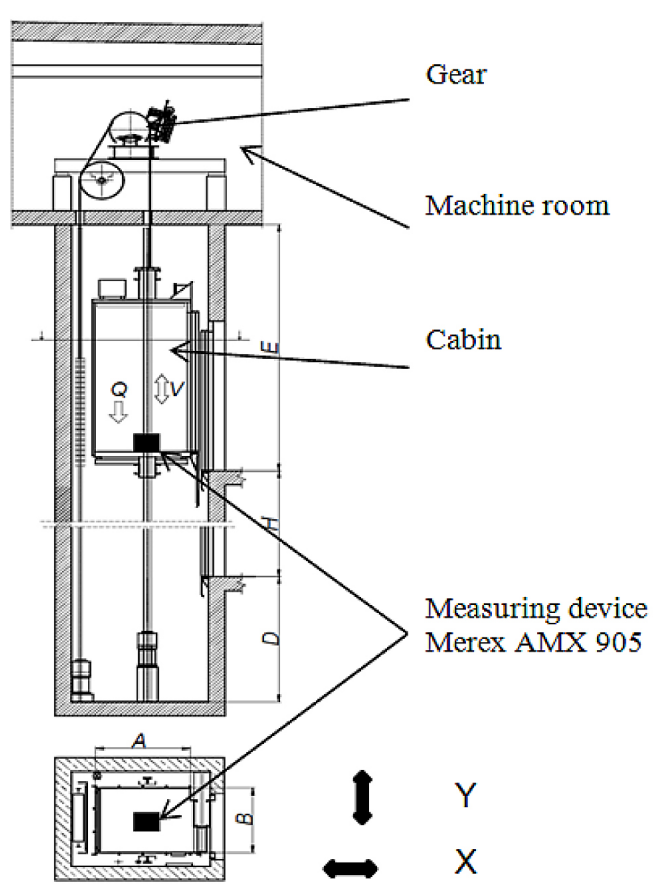

Fig. 2. The passenger lift scheme: A - the cabin depth, $\mathrm{B}-$ the cabin width, D - depth of the part under the pane, $\mathrm{H}$ - lifting height, $\mathrm{E}$ - height of the part above the pane, $\mathrm{Q}$ - loading capacity, V - the movement speed. 


\section{Measuring equipment}

Measurements of the lift cabin accelerations were done on the X-axis, Y-axis, Z-axis with the use of MEREX AMX905 device by AUTOMEX company (Fig. 3). It is a microscope device used to measure accelerations and the angle of inclination of transportation centers mounting elements.

The measuring range of accelerators was $\pm 10 \mathrm{~m} / \mathrm{s}^{2}$ whereas the measurement resolution is $\pm 0,01 \mathrm{~m} / \mathrm{s}^{2}$. Sampling frequency was $10 \mathrm{~Hz}$.

Measurements of the sound volume were performed with the use of Bruel\&Kjaer (B\&K) 2260 Investigator equipped with $\mathrm{B} \& \mathrm{~K} 3595$ double microphone probe for sound volume. The above mentioned analyzer is the one among a few devices that can measure the energetic form of the sound pressure in the actual conditions (outside laboratory). A total measuring system consists of B\&K 3595 double microphone probe, 2260 Investigator and the installed BZ7205 software allowing to measure the sound volume via the intensity method. The probe measures the values of pressures in two microphones isolated with a separator. Then, the signals from them are transmitted to a device processor where the calculations necessary to find the sound volume are made.

\section{Tests methodology}

In order to ensure optimum measuring conditions the lifting devices were withdrawn from operation. Once measuring equipment was installed inside the lifting devices a series of courses were done; the sequence was repeated three times - the journey from the lowest stop to the highest one as well as return to the lowest stop (Fig. 4). Such parameters were measured as the cabin accelerations on $\mathrm{X}$-axis, $\mathrm{Y}$-axis, $\mathrm{Z}$-axis, the sound pressure and the sound power generated by respective walls of the cabin.

Accelerations on $\mathrm{X}$-axis, Y-axis, Z-axis were measured with Merex AMX905 device which was installed (located and leveled) on the intersection of the floor diagonals. A sequence of measuring movements was performed. The place where the measuring device was located is presented in Figure 2.

Measurement of the acoustic parameters in the passenger lift cabins is difficult due to their small dimensions. The existing acoustic conditions of the near field significantly hinder the application of single microphone meters of the free field sound pressure. It is caused by hindered se- lection of a proper measuring point. This situation happens at distances smaller than the wave length of the lowest emitted frequencies or when the measuring microphone is placed at the distance smaller than the biggest, double size source of sound. In such cases the acoustic measurements method requires to be changed into the energetic method. The energetic equivalents of the sound pressure constitute the sound volume and strength. LI sound volume is defined with the use of the following dependencies:

$$
L_{I}=10 \log \frac{I}{I_{0}},
$$

where: I - the sound volume in the applicable point of environment $\left[\mathrm{W} / \mathrm{m}^{2}\right]$, $\mathrm{I}_{0}-$ the reference volume $\mathrm{I}_{0}=1\left[\mathrm{pW} / \mathrm{m}^{2}\right]$.

The level of the sound power of a given Lw source can be determined with the following dependence:

$$
L_{W}=10 \log \frac{W}{W_{0}}
$$

where: $\mathrm{W}-$ the sound power of a given source $[\mathrm{W}]$, $\mathrm{W}_{0}$ - the reference power $\mathrm{W}_{0}=1[\mathrm{pW}]$.

Each of the above listed values, describing the acoustic condition in a given point is based on the logarithmic scale what constitutes natural connection with a human feeling of linear decrease of the sound volume together with the pressure logarithm increase or the sound intensity (WeberFechner's rule) (Sound Intensity Software BZ 7205 Technical Documentation, Bruel\&Kjaer Sound \& Vibration Measurement A/S 1997).

The applied BruelKjaer 2260 Investigator analyzer equipped with B\&K 3595 double microphone probe for the sound volume was used to perform measurements because as it was mentioned earlier, it is one out of few devices that is able to measure the energetic form of the sound pressure under the real conditions (outside the Laboratory). The below dependencies are used for the above. When Euler's (3) equation is used then dependencies are based on the particles speed measurement. The particles are connected with the pressure gradient (rate, at which a temporary pressure changes together with distance) which is presented in Figure 3.

$$
v=\frac{-1}{\rho} \int \frac{\delta p}{\delta r} d t
$$




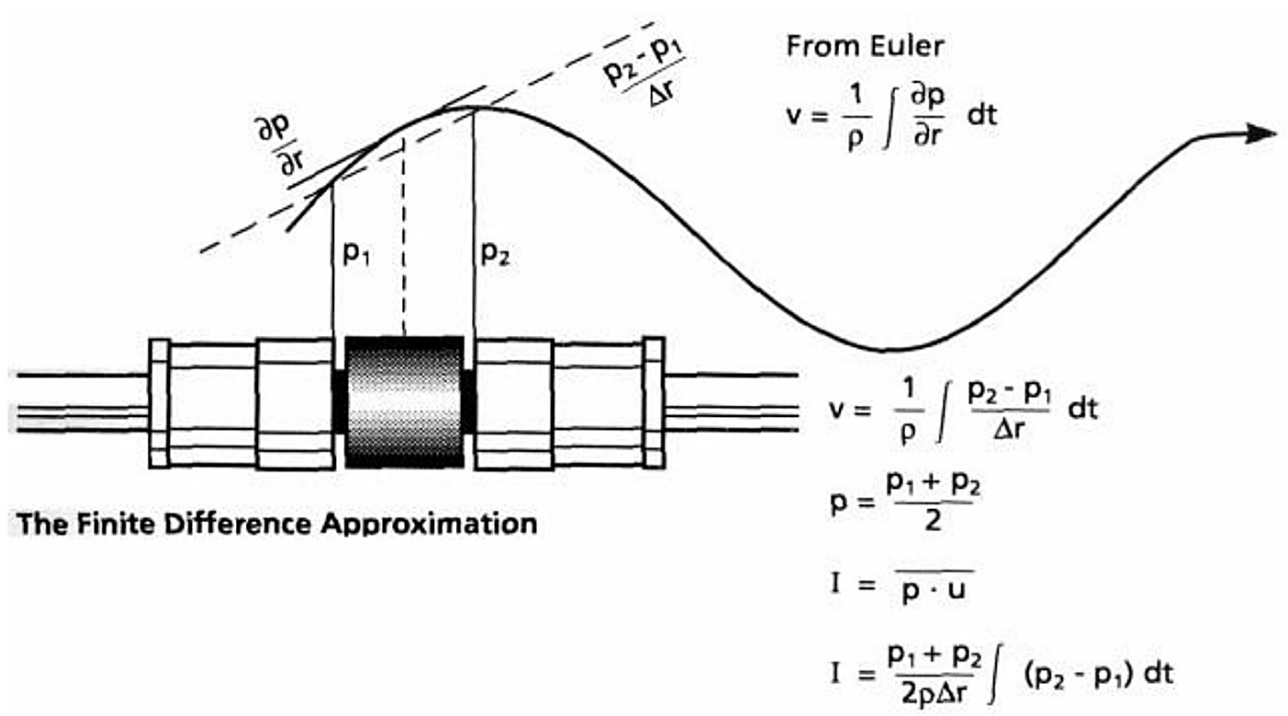

Fig. 3. The pressure gradient is approximated by using two closely spaced pressure microphones face-to-face [13]

Pressure gradient is a continuous function thanks to which the curve visible in Figure 5 changes smoothly. With the use of two microphones located close to each other the rapprochement straight line can be obtained versus the pressures gradient by making the calculation of the pressures remainder and dividing by the distance between them.

$$
\begin{gathered}
v=\frac{-1}{\rho} \int \frac{p_{2}-p_{1}}{\Delta r} d t \\
p=\frac{p_{1}+p_{2}}{2}
\end{gathered}
$$

The measurements of the sound power were performed in accordance with ISO 96142:1996 "Acoustics standard. Determination of sound power levels of noise sources using sound intensity. Measurement by scanning" The microphones were isolated with a separator of $12 \mathrm{~mm}$ length. On the basis of signals transmitted from double microphone probe of the sound source average scanning time and the value of tested surface defined field, the internal device processor measured the sound power. This method also allows to establish direction of the energy flow [13]. Prior to each series of testing the analyzer was calibrated with B\&K 4231 calibrator. The sound level was presented directly in $\mathrm{dB}$ via the application of Lin/Log transducer as well as with the use of A correction characteristic to correlate the received values with subjective sense of feeling in terms of sound volume for peoples' ears.

\section{Plan of tests}

The performed tests of accelerations as well as the power and sound pressure aimed at determining the location of main emission sources of those parameters and verifying the impact of the lift subassys operating wear and tear on measured values. Moreover, the tests purpose was to identify how the change of accelerations value influences the acoustic parameters change. For that purpose the following parameters were measured:

- $\mathrm{A} / \mathrm{G}(\mathrm{X}, \mathrm{Y}, \mathrm{Z})\left[\mathrm{m} / \mathrm{s}^{2}\right]$ - accelerations / delays in $\mathrm{X}, \mathrm{Y}, \mathrm{Z}$ axes,

- $\mathrm{Lp}(\mathrm{A})[\mathrm{dB}]-$ the level of sound pressure with A correction curve,

- $\mathrm{Lp}(\mathrm{L})[\mathrm{dB}]-$ the level of sound pressure without correction curve,

- $\mathrm{Lw}(\mathrm{L})[\mathrm{dB}]$ - the sound power emitted by the cabin walls without correction curve,

- SPL $[\mathrm{dB}]$ - the spectral analysis of the sound pressure in $1 / 3^{\text {rd }}$ octave bands (sound pressure level).

The conducted measurements are presented in Table 2.

Three times measurements of accelerations and the sound volume were performed simulta-

Table 2. Values measured in respective lifts

\begin{tabular}{|l|c|c|c|c|c|}
\hline & $\begin{array}{c}\mathrm{A} / \mathrm{G}(\mathrm{X}, \mathrm{Y}, \mathrm{Z}) \\
{[\mathrm{m} / \mathrm{s} 2]}\end{array}$ & $\begin{array}{c}\mathrm{Lp}(\mathrm{A}) \\
{[\mathrm{dB}]}\end{array}$ & $\begin{array}{c}\mathrm{Lp}(\mathrm{L}) \\
{[\mathrm{dB}]}\end{array}$ & $\begin{array}{c}\mathrm{Lw}(\mathrm{L}) \\
{[\mathrm{dB}]}\end{array}$ & $\begin{array}{c}\mathrm{SPL} \\
{[\mathrm{dB}]}\end{array}$ \\
\hline The lift 1 & + & + & + & + & + \\
\hline The lift 2 & + & + & + & + & + \\
\hline
\end{tabular}




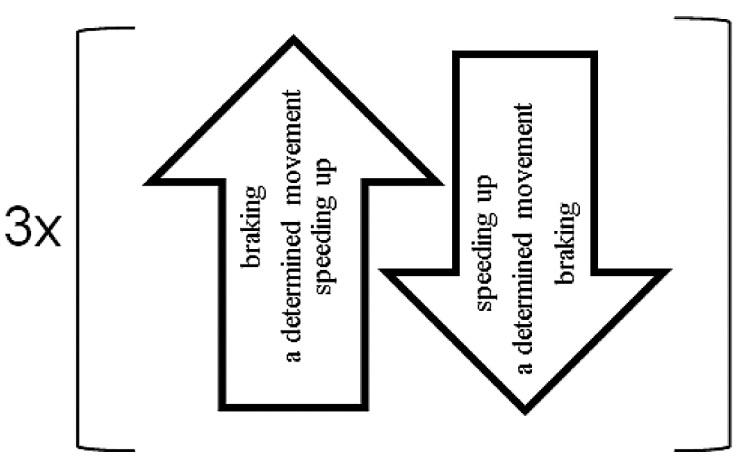

Fig. 4. Sequence of the rides during the measurements execution

neously for each lift as per the sequence presented in Figure 4. The results analysis gave chance to determine the location of the sound emission sources and to plan construction modifications aiming at improving the level of the passengers' comfort while travelling in the lift. Once the changes were implemented to the construction of the frame-cabin system the whole sequence of measurements was repeated.

\section{ANALYSIS THE TESTS RESULTS}

Acoustic phenomena appearing in the cabins of the tested lifts are closely connected with physical phenomena taking place during the lift movement such as the cabin accelerations on Xaxis, $\mathrm{Y}$-axis and $\mathrm{Z}$-axis. The accelerations charts of tested lifts in vertical $\mathrm{Z}$-axis are presented in Figure 5 within one complete ride cycle. The first peak visible in Figure 5 is responsible for the lift acceleration during the movement upwards, whereas the second peak directed in the opposite side is responsible for the acceleration (start-up of the movement) downwards. Visible non-linear declinations between the two peaks are probably caused by the working elements of suspension due to which the lift cabin during the movement can demonstrate additional accelerations in the direction of Z-axis coming, for example, from moving weight inside the cabin (e.g. the passengers' movement). The accelerations values on $\mathrm{Z}$-axis have lower meaning due to the fact that these are the values that can be controlled (by regulating the power drive control). More important are the values of accelerations on $\mathrm{X}$-axis and $\mathrm{Y}$-axis because these are the accelerations which are not desirable and the change in their value gives the evidence on the wear and tear of the lift slides system. Side accelerations in the directions $\mathrm{X}, \mathrm{Y}$ recorded during the journey in tested devices are presented in Figure 6.

Cabin accelerations in $\mathrm{X}$-axis and $\mathrm{Y}$-axis direction are caused by roughnesses on the lift slides (among others where they join) or they can come from distorted material of the slides rollers due to a long lasting pressure generated by downtime of device. The cabin accelerations in $\mathrm{X}$-axis and $\mathrm{Y}$-axis are also caused by the clearances resulting from the rollers' wear and tear (Fig. 1). The Figure 7 illustrates a graphic form of the recorded measurements results of accelerations in $\mathrm{X}$ and $\mathrm{Y}$ axes after the construction modernization. The slides frames of the objects subject to tests were replaced with new elements with the possibility to regulate the clearance between the rollers. In order to determine the influence of the frames design changes on the level of vibrations and the sound emission it was decided to install the old elements of the rollers. After the installation, the system was properly adjusted in accordance with the manufacturer's manual and another series of tests was initiated.

The performed modernization of the slides did not influence the value of $\mathrm{Z}$ axis accelerations. Whereas, the values of accelerations in $\mathrm{X}$ and $\mathrm{Y}$ axes, which are visible in Figure 7, after the elimination of the slides clearances, significantly decreased in comparison to the first series of tests presented in Figure 6.

All accelerations which are not caused by the power drive intentionally in Z-axis direction should be treated as undesirable because they are one of the energy dissipation forms, the effect of which is the sound emission in the cabin and the passengers comfort decrease.

With respect to the fact that in the lift pit it is very difficult to eliminate the accelerations in $\mathrm{X}$ and $\mathrm{Y}$ axes completely as well as due to the fact that most often the lift cabin is made of panel thin-walled elements susceptible to resonating, what consequently can significantly lead to the increase of the acoustic emission level, it was decided to modernize the internal walls of the lift cabin. The cabin panels were taped with the bands of hydroinsulating material what has been presented in Figure 8. It is made of asphalt and polymer mixture, which is insulating and sticky and applied on one side of the aluminum foil carrying element. 


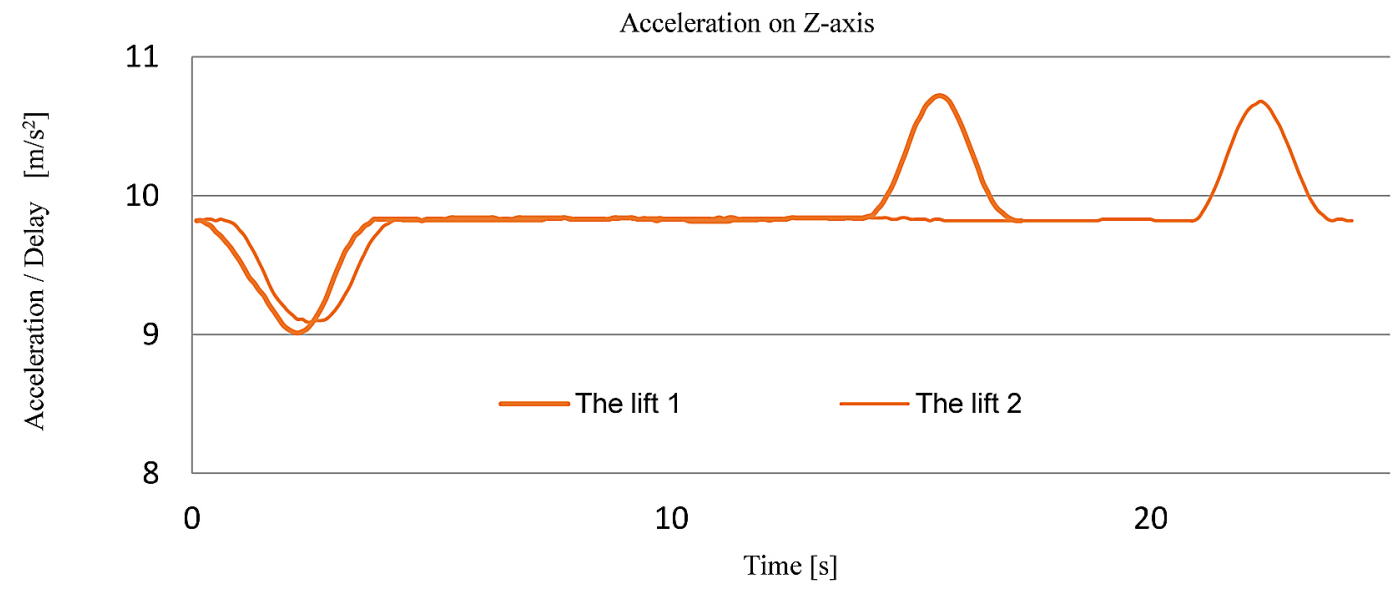

Fig. 5. Breakdown of accelerations in Z-axis for tested lifts.

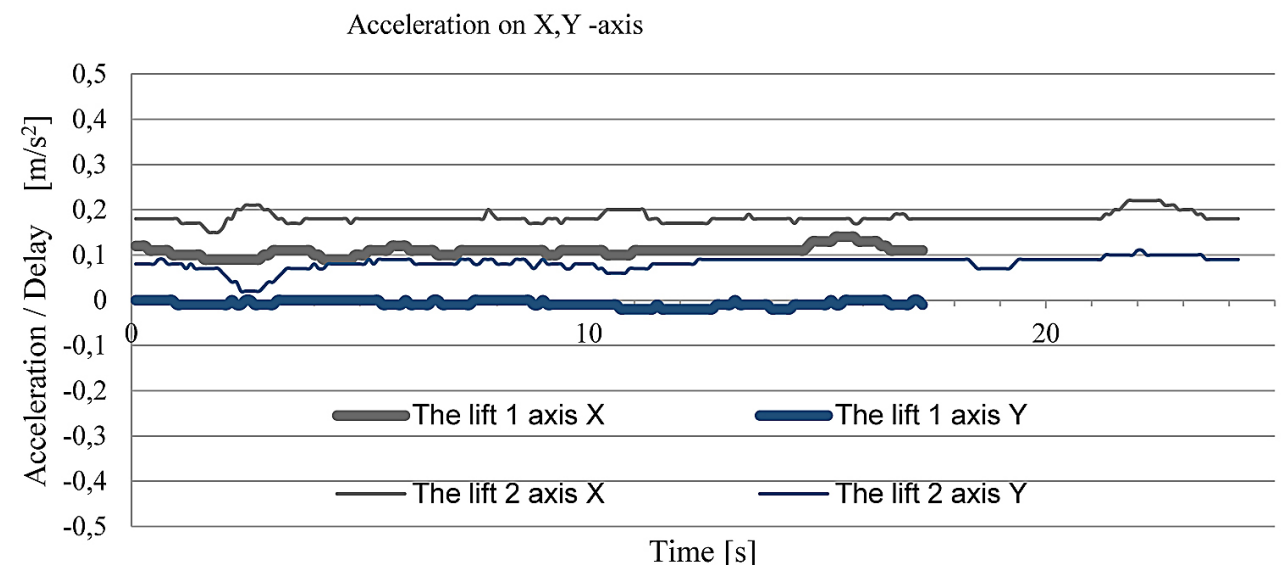

Fig. 6. Breakdown of accelerations in X, Y-axis for tested lifts.

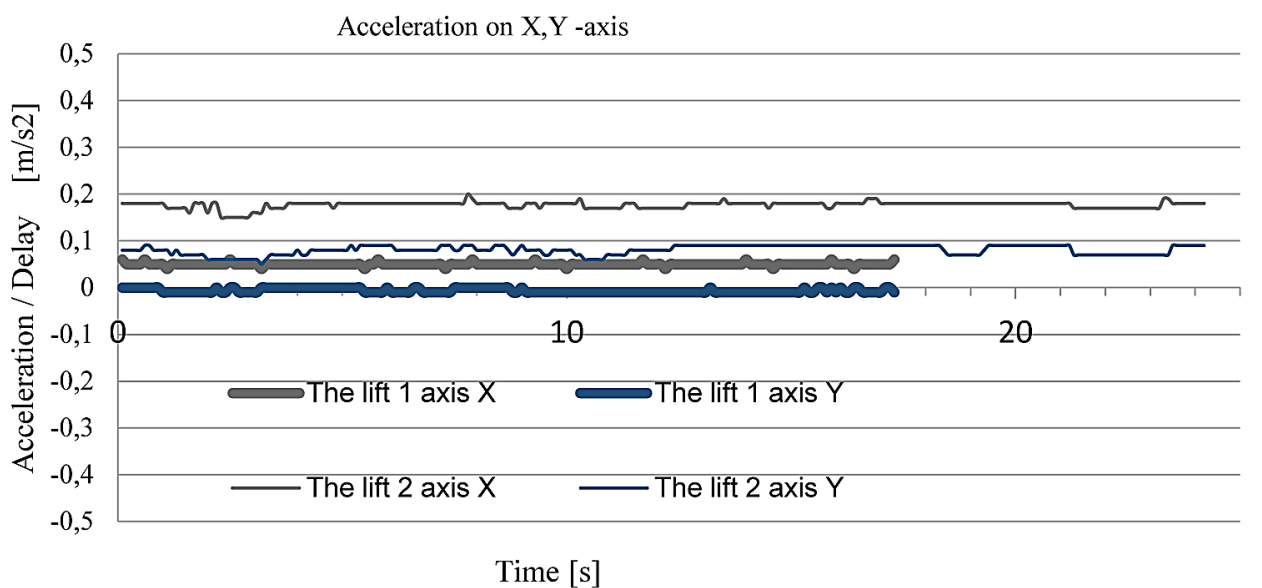

Fig. 7. Breakdown of accelerations in X, Y-axis for the lifts after modernization

The physical phenomena appearing in the cabins of tested lifts are closely connected with acoustic phenomena taking place during the lift movement such as the sound volume and the sound power generated by respective walls of the cabin. The results of the sound $\mathrm{Lp}[\mathrm{dB}]$ pressure level measurements with double channel method are compiled in Table 3. The respective values from the Table present the values measured by both microphones (ch1 and ch2) and a calculated average value for both measurements. The values in the brackets come from the repeated measurements once the modifications were implemented (the slides frames replaced and the cabin walls taped with the soundproof tape). The measuring microphone was located at $1.8 \mathrm{~m}$ height in 


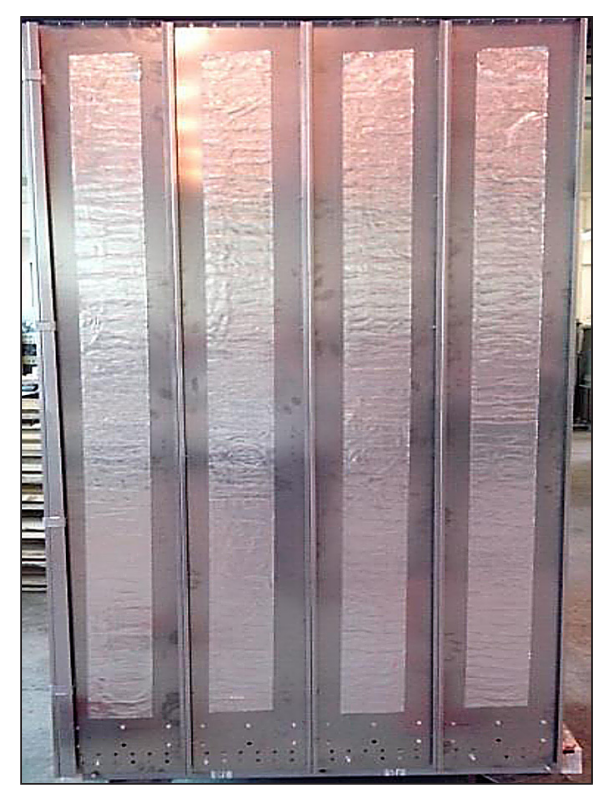

Fig. 8. The solution to cover the cabin walls with the soundproof tape

the middle of the cabin. The measurements were performed both without the correction curve (Lin value) as well as with A correction curve in order to demonstrate the optimal correlation which is equal to a human being's ear perception. Such a table is the best way to illustrate the fact that even though there are relatively high values of the sound pressure level, its frequency causes that the subjective perception of the loudness by a human being's ear is much lower.

Subjective perception of the sound emission depends, to a large extent, on its frequency which was presented in Figure 9, containing a combination of correction curves.

While analyzing the values presented in Table 3 it can be stated that the higher level of the sound pressure appears in the lift 1 comparing with the lift 2 , even though technical parameters are similar. It can result from a higher wear and tear of the device's elements caused by the fact that a given device was operated longer. The slides made of steel rollers covered with "vulkollan" type of material are the carriageable elements of the frame-cabin

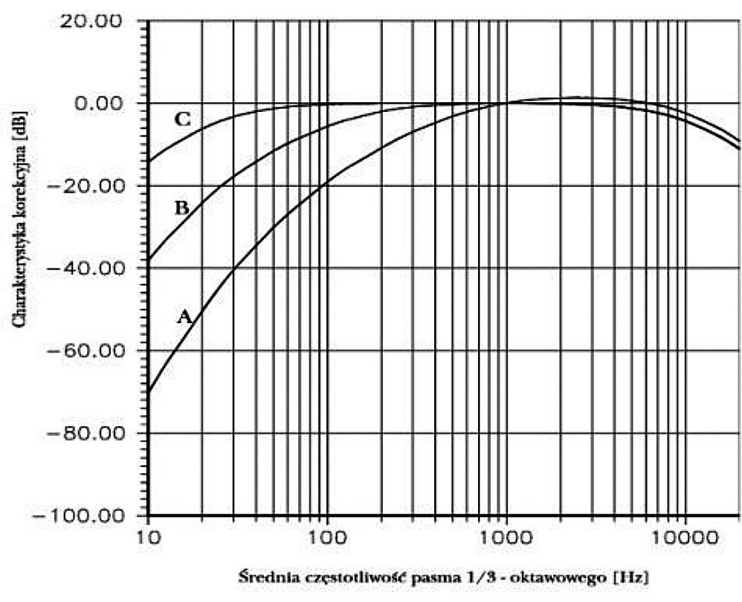

Fig. 9. Correction curves used in acoustic measurements

system in terms of the tested devices. Each of the three rollers coming into the slide has a ball antifriction bearing and slides mounted in four places to the cabin frame, move along the steel slides. The wear and tear of the slides caused by the worn out rollers or damaged bearings lead to the increased acoustic emission which, as a result of the vibration transfer, is received by the cabin walls. The results of recorded levels of the sound pressure presented in Table 3 demonstrate the significance of the lifting devices modernization. Modification of the guiding system and the application of soundproofing elements on the internal panels of the cabin walls resulted, in case of the lift No. 1, with the sound emission value drop by $4 \mathrm{~dB}$ what can be clearly noticed by the human being's ear. A smaller change in the recorded values of sound pressure in the lift No. 2 is probably caused by the fact that before design modification the lift slides had, in comparison to the lift No. 1, lower values of clearances connected with shorter period of their operation. The increased level of sound emission can be also caused by the carrying lines which, when coming out from the friction wheel of an excessive wear and tear (recognized by worn out wedge grooves),

Table 3. Measurement of the sound pressure level $\mathrm{Lp}[\mathrm{dB}]$ with double channel method (two measuring microphones)

\begin{tabular}{lccccccc}
\multicolumn{1}{c}{ Correction method } & The lift 1 ch1 & The lift 1 ch2 & $\begin{array}{c}\text { The lift } 1 \text { ave- } \\
\text { rage value }\end{array}$ & The lift 2 ch1 & The lift 2 ch2 & $\begin{array}{c}\text { The lift } 2 \\
\text { average } \\
\text { value }\end{array}$ \\
$\begin{array}{l}\text { With "A" cor- } \\
\text { rection curve }\end{array} \quad \mathrm{Lp}(\mathrm{A})[\mathrm{dB}]$ & $59,7(56,1)$ & $60,6(56,8)$ & $60,15(56,45)$ & $54,9(53,1)$ & $55,3(53,4)$ & $55,1(53,25)$ \\
Lin & $\mathrm{Lp}(\mathrm{L})[\mathrm{dB}]$ & $79,4(75,5)$ & $79,9(76,1)$ & $79,65(75,8)$ & $81,3(79,1)$ & $81,7(79,3)$ & $81,5(79,2)$
\end{tabular}


start vibratingwith the amplitude dependent on the line length leading to uncomfortable effect, which is heard by the passenger and described as "cracking".

The slides and lines operating wear and tear are not so obviously noticed after the analysis of data values included in Table 3. One of the reasons of this ambiguity was the fact that measuring method for the free field was applied. However, the spectral analysis (Fig. 10 and 11) of recorded data shows a clear impact of the operation length on respective ranges of emitted sound frequencies.

On the basis of the above presented spectral breakdowns in $1 / 3$ rd octave bands, significant increase of the sound emission regarding the lift 1 in a range from 100 to $4000[\mathrm{~Hz}]$ can be noticed.

Within the applicable frequencies range a human being's ear is especially sensitive to the receipt of sound stimuli recognized as noise - it is presented in Figure 9 graphically. The reduction of sound emission is clearly noticeable after the implementation of design modifications.

The application of the analyzer equipped with double microphone intensity probe allowed us to perform the measurement in the near field of the

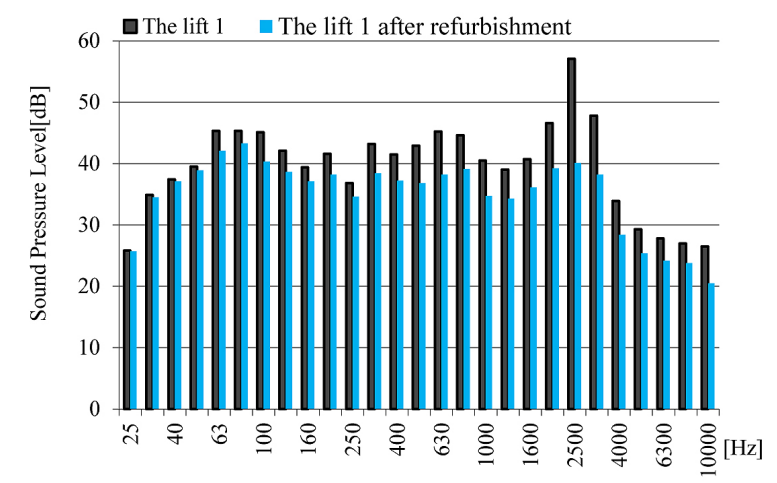

Fig. 10. Spectral analysis of the sound (SPL) in $1 / 3 r d$ octave bands for the lift 1

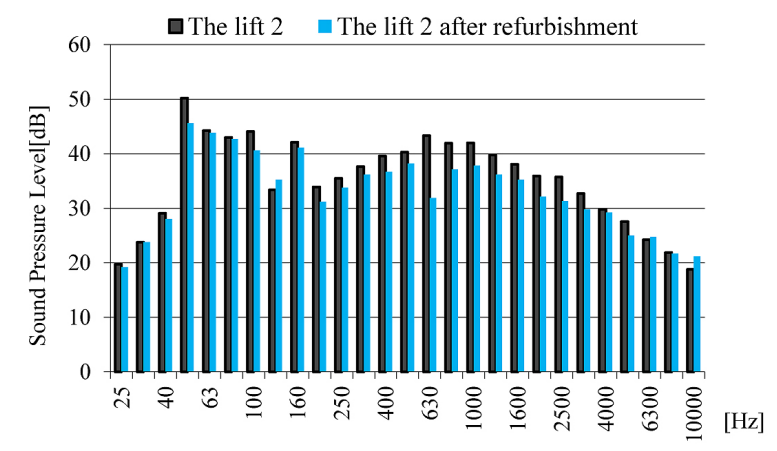

Fig. 11. Spectral analysis of the sound (SPL) in $1 / 3 \mathrm{rd}$ octave bands for the lift 2 sound sources. The scanning method, compliant with ISO 9614-2:1996 standard, of respective walls in the tested objects cabins gave chance to determine a total power of sound $\mathrm{Lw}(\mathrm{L})$ emitted by tested lifts. The measurements results are included in Table 4 whereas Table 5 provides the partial breakdown of the sound powers emitted by respective walls. Data clearly indicates the increase of emitted sound volume in case of the lift cabin with a longer period of its operation as well as the drop of the sound volume after the installation of new slides and acoustic insulation for the cabin walls.

Table 4. The power of sound emitted by the cabin walls

\begin{tabular}{|c|c|c|c|}
\hline \multicolumn{2}{|c|}{ The lift serial number } & The lift 1 & The lift 2 \\
\hline $\begin{array}{l}\text { otal volume emit- } \\
\text { ed by } 5 \text { walls lin }\end{array}$ & $\operatorname{Lw}($ & $\begin{array}{c}72,8 \\
(69.1)\end{array}$ & $\begin{array}{l}68,5 \\
(66.4)\end{array}$ \\
\hline
\end{tabular}

Table 5. Partial powers of the sound emitted by respective walls

\begin{tabular}{cccc}
\multicolumn{2}{l}{ The lift serial number } & The lift 1 & The lift 2 \\
Front & $\mathrm{Lw}(\mathrm{L})[\mathrm{dB}]$ & $62.4(61.1)$ & $58.9(58.1)$ \\
Back & $\mathrm{Lw}(\mathrm{L})[\mathrm{dB}]$ & $70.6(68.2)$ & $72.4(71.2)$ \\
Left & $\mathrm{Lw}(\mathrm{L})[\mathrm{dB}]$ & $64.1(61.2)$ & $67.5(66.3)$ \\
Right & $\mathrm{Lw}(\mathrm{L})[\mathrm{dB}]$ & $63.3(60.2)$ & $67.2(66.2)$ \\
Top & $\mathrm{Lw}(\mathrm{L})[\mathrm{dB}]$ & $59.7(58.2)$ & $73.8(72.1)$
\end{tabular}

Further, detailed tests probably will allow the authors to localize the main sources of the sound emission and to determine the border of the drive-carriagable elements applicability for further operation, contributing at the same time, to the increase of safety and improvement of the passenger comfort.

\section{CONCLUSIONS}

On the basis of conducted experimental tests the following can be stated:

1. Accelerations in the axis which is different than the one of the lift cabin movement, driven by the power drive, are the form of dissipation of energy increasing the energy consumption by the whole device and decreasing the comfort of travelling.

2. The wear and tear of the carriageable elements of the lift have the impact on the increase of sound which is emitted by the lift cabin walls and which is perceptible by the passengers as the increased loudness. 
3. The measurement of the sound volume with energetic methods with the use of the double microphone probe to measure the sound is presently the best acoustic measurements method for the passenger lifts cabins;

4. The duration of the device operation has a significant impact on respective sound bands frequencies emitted by the lift cabin;

5. The recorded power of sound emitted by the cabin, which was in use three years longer, has increased by over $4 \mathrm{~dB}$;

6. The application of design modifications for the slides frames and the use of the soundproofing material on the cabin internal panels surface gave the chance to reduce the level of sound emission by app. $4 \mathrm{~dB}$, what significantly increased the comfort of travelling in the lift;

7. Clearances appearing in the lift carriageable system contribute to the presence of side accelerations that can be perceived by a human being as trembling cabin which increases together with the level of the slides wear and tear;

8. Tests of the acoustic emission and accelerations appearing during the lift movement can prove the operational wear and tear of the carriageable system and power drive elements;

9. The system vibrations and acoustic emission level measured in an appropriate place can be a diagnostic parameter in order to evaluate a device technical condition.

10.The factors tested in the article do not cause unfavorable health consequences in the human body when the contact with them is occasional and sporadic, whereas the time of exposition is short. Nevertheless, it was proved that in the lift which is operated longer a clear increase of the sound and vibrations perceptible by a human being takes place. It can be assumed that in the future development of science, technique and progress in mechanical devices construction will be conducive to eliminate or it will even exclude the negative impact of noise and vibrations on the human body and the comfort of those devices operation.

\section{REFERENCES}

1. Burov A. A., Kosenko I. I., Troger H. On Periodic Motions of an Orbital Dumbbell-Shaped Body with a Cabin-Elevator. Mechanics of Solids, 47 (3), 2012, 269-284.
2. Lonkwic P., Gardyński L. Testing polymer rollers memory in the context of passenger lift car comfort. Journal of Vibroegineering, 1, 2014, $225-230$.

3. Hirose M., Kobayashi T. Analyses and Modeling of Ultra-Wideband On-Body Propagation Channels Depending on Population Density within an Elevator Cabin. IEICE Transactions on fundamentals of electronics communications and computer sciences, E97A (1), 2014, 94-100.

4. Lonkwic P., Szydło K., Molski Sz. The impact of progressive gear geometry on the braking distance length under changeable operating conditions, Advances in Science and Technology Research Journal, 10 (29), 2016, 161-167, DOI: $10.12913 / 22998624 / 61948$.

5. Lonkwic P., Różyło P., Dębski H. Analysis of the loading impact on the stresses value of the progressive gear body with the use of finite-element method. Eksploatacja i Niezawodność, 17 (4), 2015, 542-548.

6. Lonkwic P., Szydło K. Selected Parameters of the Work of Speed Limiter Line Straining System in a Frictional Lift. Advances in Science and Technology, 8 (21), 2014, 73-77.

7. Polish Standard PN EN 81.1+A3, Safety Regulations Concerning the Structure and Installation of Lifts, Part I. Electric Lifts.

8. Rijanto E., Muramatsu T., Tagawa Y. Control of elevator having parametric vibration using LPV control method: Simulation study in the case of constant vertical velocity. Paper presented at the IEEE Conference on Control Applications - Proceedings, 1, 1999, 527-532.

9. Shin B., Yoon S., Lee H. Koo, YS. Jeong Y., Kang I. Mechanical Properties and Molecular Structure of Rubber Materials with Different Hardnesses for Vibration Isolation of Elevator Cabins. Korean Journal of Metals and Materials, 51 (10), 2013, 713-718.

10. Lotko W., Maciąg P., Maciąg M., New method to evaluate the machines and devices noise, Scientific and Technical Conference Materials, A vehicle versus environment, Radom 1997 (in Polish).

11. Longwic R., Maciąg P., Szydło K., Methodology of the noise emission measuring in the passenger lift cabins. Logistics, 6, 2014 (in Polish), 6809-6817.

12. Lonkwic P., Szydło K., Longwic R, Maciąg P., Method to limit the noise emission emitted from thin-walled products. Logistics, Issue: 6, 2014 (in Polish), 6818-6827.

13. Sound Intensity Software BZ 7205 Technical Documentation, Bruel\&Kjaer Sound \& Vibration Measurement A/S, 1997. 